\title{
NEURAL PROJECTIONS FROM NUCLEUS ACCUMBENS TO GLOBUS PALLIDUS, SUBSTANTIA INNOMINATA, AND LATERAL PREOPTIC- LATERAL HYPOTHALAMIC AREA: AN ANATOMICAL AND ELECTROPHYSIOLOGICAL INVESTIGATION IN THE RAT ${ }^{1}$
}

\author{
G. J. MOGENSON, L. W. SWANSON, ${ }^{2}$ AND M. WU \\ Department of Physiology, University of Western Ontario, London, Ontario, Canada N6A 5C1 and The Salk Institute, \\ San Diego, California 92138
}

Received April 12, 1982; Revised July 21, 1982; Accepted July 26, 1982

\begin{abstract}
The anatomical organization and electrophysiological characteristics of a projection from the nucleus accumbens to anteroventral parts of the globus pallidus and to a subpallidal region that includes the substantia innominata (SI), the lateral preoptic area (LPO), and anterior parts of the lateral hypothalamic area (LHA) were investigated in the rat. Autoradiographic experiments, with injections of ${ }^{3} \mathrm{H}$-proline into different sites in the nucleus accumbens and adjacent caudoputamen, indicate that the descending fibers are organized topographically along both mediolateral and dorsoventral gradients, although labeled fibers from adjacent regions of the nucleus accumbens overlap considerably in the ventral globus pallidus and subpallidal region. Injections confined to the caudoputaman only labeled fibers in the globus pallidus. Retrograde transport experiments with the marker true blue confirmed that only the nucleus accumbens projects to the subpallidal region and that the caudoputamen projects upon the glubus pallidus in a topographically organized manner. In electrophysiological recording experiments single pulse stimulation $(0.1$ to $0.7 \mathrm{~mA} ; 0.15 \mathrm{msec}$ duration) of the nucleus accumbens changed the discharge rate of single neurons in the ventral globus pallidus and in the SI, LPO, and LHA. Typically, the responses were inhibition of neuronal discharge with latencies of 6 to $18 \mathrm{msec}$. Single pulse stimulation of the dorsolateral caudoputamen altered the discharge rate of single neurons in dorsal regions of the globus pallidus, with inhibition being the most frequently observed response. The results of these anatomical and electrophysiological experiments are complementary and indicate that fibers from the nucleus accumbens innervate the anteroventral region of the globus pallidus as well as the subpallidal region, while most fibers of the caudoputamen innervate the globus pallidus but not the subpallidal region.

It appears, therefore, that these two components of the striatum have different output connections. The possible functional significance of these findings is discussed in relation to the projections of the subpallidal region, which may include an output to the mesencephalic locomotor region, and in relation to the nucleus accumbens afferents from the amygdala and hippocampal formation.
\end{abstract}

The caudoputamen and nucleus accumbens together form the striatum, and anatomical studies have shown that both components project to the globus pallidus (GP) and to the substantia nigra (see Voneida, 1960; Szabo,

${ }^{1}$ This work was supported in part by Medical Research Council of Canada Grant MT-1866 to G. J. M. and by Grants NS-16686 (from the National Institutes of Health) and DA-00259 (from the Alcohol, Drug Abuse, and Mental Health Administration), and by the Clayton Foundation for Research-California Division to L. W. S. L. W. S. is a Clayton Foundation Investigator.

${ }^{2}$ To whom correspondence should be addressed at The Salk Instiute, P. O. Box 85800, San Diego, CA 92138.
1962; Cowan and Powell, 1966; Swanson and Cowan, 1975; Nauta et al., 1978). Electrophysiological studies have confirmed a projection from the nucleus accumbens to ventral parts of the globus pallidus $\left(\mathrm{GP}_{\mathrm{v}}\right)$ (Dray and Oakley, 1978; Jones and Mogenson, 1980b), and the results of neurochemical experiments indicate that at least one component of this projection is GABAergic (Nagy et al., 1978; Fonnum and Walaas, 1981), a conclusion that is strengthened by the observation that iontophoretic application of the GABA antagonist, picrotoxin, reverses the inhibition of $\mathrm{GP}_{\mathrm{v}}$ neurons following stimulation of the nucleus accumbens (Jones and Mogenson, 1980b). Since the nucleus accumbens receives substantial inputs 
from the hippocampal formation (Swanson and Cowan, 1977) and the amygdala (Krettek and Price, 1978; Newman and Winans, 1980), this evidence has led to the suggestion that it may serve as an important link between the limbic system on the one hand and somatomotor control systems on the other (Swanson and Cowan, 1975; Mogenson et al., 1980; Swanson and Mogenson, 1981).

Despite the similarities just mentioned, there are differences in the course taken by projections from the caudoputamen and nucleus accumbens. Perhaps the most obvious difference is that fibers from the caudoputamen travel to the substantia nigra through medial parts of the cerebral peduncle, while most of those from the nucleus accumbens descend through lateral parts of the medial forebrain bundle in the substantia innominata (SI), lateral preoptic area (LPO), and lateral hypothalamic area (LHA). The main objective of the present study was to investigate further the projection from the nucleus accumbens to the $\mathrm{GP}_{\mathrm{v}}$ and to determine whether some of the descending fibers in the medial forebrain bundle may also end in the SI, LPO, and LHA. Anatomical techniques were used to determine the extent and topographical organization of fibers from the nucleus accumbens that enter the $G P_{v}$ and the subpallidal region below it that includes the SI, LPO, and the anterior part of the LHA. Since the anatomical methods used cannot demonstrate directly the existence of functional contacts, electrophysiological recordings were made from single neurons in these regions to map the location of units that respond to electrical stimulation of the nucleus accumbens. Recordings also were made from neurons in dorsal parts of the GP $\left(G_{d}\right)$ before the microelectrode was lowered to the $\mathrm{GP}_{\mathrm{v}}$ and then to the subpallidal region. This provided an opportunity to investigate the effects of nucleus accumbens stimulation on the activity of neurons in the $\mathrm{GP}_{\mathrm{d}}$. Since the $\mathrm{GP}_{\mathrm{d}}$ receives strong connections from the caudoputamen (Kemp and Powell, 1971; Nagy et al., 1978), the effects of electrical stimulation in he latter also were observed, and a comparison was made between the effects of stimulation in the nucleus accumbens or the caudoputamen on the activity of neurons in the $\mathrm{GP}_{\mathrm{v}}$, the subpallidal region, and the $\mathrm{GP}_{\mathrm{d}}$.

\section{Materials and Methods}

Anatomical experiments. Adult male albino rats were used. In one group of experiments $(N=10)$, each animal received a single 20 - to $40-\mathrm{nl}$ injection of ${ }^{3} \mathrm{H}$-proline (L2,3- ${ }^{3} \mathrm{H}$-proline; specific activity, $24 \mathrm{Ci} / \mathrm{mmol}$; New England Nuclear) in either the nucleus accumbens or adjacent parts of the caudoputamen. The injections were made stereotaxically with a $1-\mu \mathrm{l}$ Hamilton microsyringe over a 10 - to 15 -min period, and the ${ }^{3} \mathrm{H}$-proline was reconstituted in sterile saline to a final concentration of $20 \mu \mathrm{Ci} / \mu \mathrm{l}$. One to 3 days later, the animals were perfused transcardially with a buffered $10 \%$ formalin solution, and the brains were processed for autoradiography according to the method described by Cowan et al. (1972). Several of these brains were described in an earlier brief report on the connections of the nucleus accumbens (Swanson and Cowan, 1975).

In a second group of experiments $(N=16)$, each animal received a single 20 -nl injection of the retrogradely transported fluorescent label true blue $(2 \% \mathrm{w} / \mathrm{v}$, in distilled water) in the region of the globus pallidus, substantia innominata, and lateral preoptic area. The injections were made stereotaxically with a $1-\mu$ l Hamilton microsyringe over a 10 -min period. Four to 7 days later, the animals were perfused transcardially with a buffered $10 \%$ formalin solution, following a brief rinse with saline, and the brains were prepared as described elsewhere (Sawchenko and Swanson, 1981). A 1-in-5 series of $30-\mu \mathrm{m}-$ thick sections through the basal ganglia was prepared, and the location of retrogradely labeled cells was determined with the aid of dark-field illumination, which reveals major fiber tracts, and/or with the aid of a fluorescent counterstain, ethidium bromide (Schmued et al., 1982), which yields a Nissl stain when excited by green (excitation filter BP530-560) light. The fluorescence material was viewed with a Leitz Dialux 20 microscope equipped with a Ploem illumination system, a 100W Hg light source, and oil objectives. True blue was viewed with filter system "A" (ultraviolet; excitation filter BP340-380), and ethidium bromide was viewed with filter system" $I_{2}$."

The normal morphology of the areas under consideration here was examined in normal series of brains that were cut in the frontal plane and that were stained in the usual way for cells (thionin), fibers (silver and Luxol fast blue), and acetylcholinesterase (see Swanson, 1976; Swanson and Cowan, 1979). From this material a standard series of drawings was constructed for plotting the results of experiments, and experimental brains were blocked in approximately the same plane of section with the aid of a simple mechanical device that guides a razor blade at a standard angle.

Electrophysiological recording experiments. Fortythree adult male albino rats weighing 250 to $300 \mathrm{gm}$ were used. They were anesthetized with urethane (1.15 to 1.2 $\mathrm{mg} / \mathrm{kg}$, i.p.) and placed in a Kopf stereotaxic apparatus with the incisor bar $2.4 \mathrm{~mm}$ below the ear bars. Rectal temperature, monitored with a model YSI-402 telethermometer (Yellow Springs Instrument Co.), was maintained at 36 to $38^{\circ} \mathrm{C}$ throughout the recording session by a radiant heat lamp. The skin, skull, and dura above the basal ganglia were carefully removed to lower the recording microelectrodes, and burr holes of 2 to $3 \mathrm{~mm}$ diameter were drilled in the skull above the nucleus accumbens and caudoputamen to permit positioning of the stimulating electrodes. The coordinates used for the nucleus accumbens were $9.4 \mathrm{~mm}$ anterior to the interaural line, $1.0 \mathrm{~mm}$ lateral to the midline, and $6.0 \mathrm{~mm}$ below the surface of the cortex; for the caudoputamen the coordinates were $8.3 \mathrm{~mm}$ anterior to the interaural line, $3.4 \mathrm{~mm}$ lateral to the midline, and $3.0 \mathrm{~mm}$ below the surface of the cortex; and for the pallidum the coordinates were 5.3 to $6.8 \mathrm{~mm}$ anterior to the interaural line, 1.5 to $3.8 \mathrm{~mm}$ lateral to the midline, and 4.3 to $8.0 \mathrm{~mm}$ below the surface of the cortex.

Stainless steel concentric electrodes (model SNE-100, Rhodes Medical Instrument) with tip separation of 0.5 $\mathrm{mm}$ were used for electrical stimulation of the nucleus accumbens and the caudoputamen. Electrical stimulation was generated by a Grass model S-44 stimulator coupled to a Grass stimulation isolation unit (model SIU 6). Square pulses of $0.15 \mathrm{msec}$ duration and 0.1 to $0.9 \mathrm{~mA}$ intensity were used. 


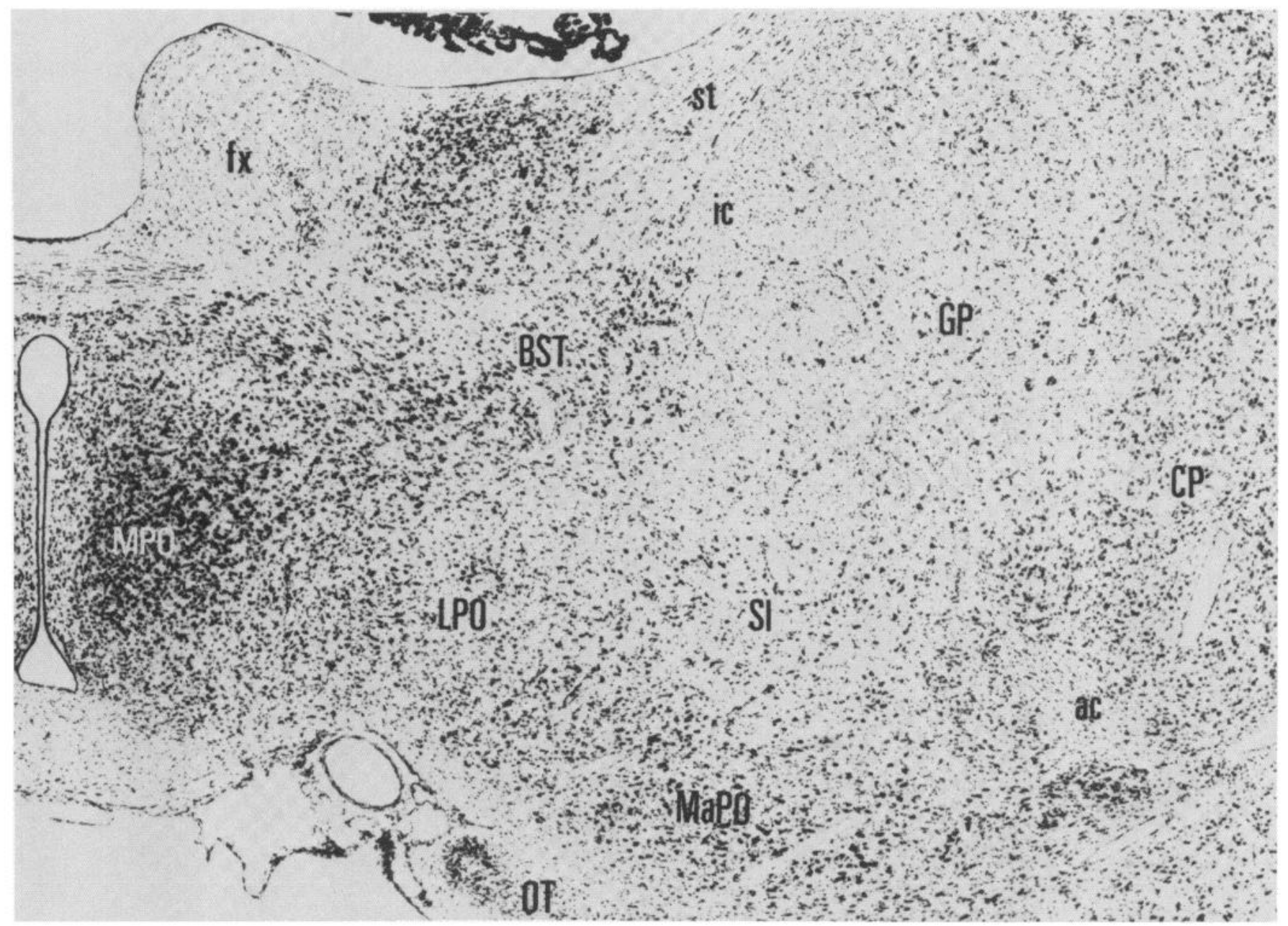

Figure $1 .^{3}$ A low power photomicrograph to show the appearance of the globus pallidus (GP), substantia innominata (SI), lateral preoptic area (LPO), and adjacent structures at the level of the anterior commissure and optic chiasm (unlabeled fiber tracts crossing the midline dorsal and ventral to the third ventricle on the left). The drawings in the second panel from the top in Figure 2 were made at this level. Nissl-stained frontal section from the rat. Magnification $\times 45$.

Glass micropipettes for extracellular recording from single neurons were made from Kimax 51 borosilicate capillaries (Fisher Scientific Co.) and were pulled to a tip diameter of 1 to $1.5 \mu \mathrm{m}$ using a Narashige microelectrode puller (Maeda and Mogenson, 1980; Yim and Mogenson, 1980). They were filled with $0.5 \mathrm{M}$ sodium acetate and $2 \%$ Pontamine Sky Blue (Glurr). The impedance of the microelectrodes was 5 to 9 megohms at $1 \mathrm{kHz}$ sine wave. Recorded action potentials were sampled on-line by a PDP-11/44 computer. The recordings were stored on magnetic disks and poststimulus histograms were compiled from data files off-line (Yim and Mogenson, 1980).

${ }^{3}$ The abbreviations used on all figures are: A, amygdala; ac, anterior commissure; AHA, anterior hypothalamic area; BST, bed nucleus of the stria terminalis; DBB, nucleus of the diagonal band; DMH, dorsomedial nucleus; EP, entopeduncular nucleus; fx, fornix; GP globus pallidus; IC, internal capsule; LHA, lateral hypothalamic area; LPO, lateral preoptic area; LS, lateral septal nucleus; MA, medial nucleus (amygdala); MaPO, magnocellular preoptic nucleus; MPO, medial preoptic area; ot, optic tract; OT, olfactory tubercle; $\mathrm{PVH}$, paraventricular nucleus; SFO, subfornical organ; SI, substantia innominata; sm, stria medullaris; SO, supraoptic nucleus; SSG, substriatal gray; VA, ventral anterior nucleus; VB, ventrobasal complex; VL, lateral ventricle; $\mathrm{VMH}$, ventromedial nucleus; V3, third ventricle; $\mathrm{ZI}$, zona incerta.
At the end of the experiment, recording sites were marked for later histological identification by ejecting Pontamine Sky Blue as an anion with a continuous DC current of 6 to $8 \mu \mathrm{A}$ for 10 to $15 \mathrm{~min}$. Stimulation sites were marked with iron deposits by passing a positive current of $10 \mu \mathrm{A}$ through the electrode for $1 \mathrm{~min}$. The animals then were sacrificed by an overdose of urethane. The brains were perfused with $50 \mathrm{ml}$ of $0.9 \%$ saline followed by $50 \mathrm{ml}$ of buffered formalin which contained $3 \%$ potassium ferrocyanide, were removed, and were postfixed in formalin for $24 \mathrm{hr}$. Transverse sections $80 \mu \mathrm{m}$ thick were made with a freezing microtome and were stained with thionin for microscopic examination to determine recording and stimulation sites.

\section{Results}

The observations from the anatomical experiments will be presented first, followed by the electrophysiological findings.

Normal morphology. An account of the morphology of the nucleus accumbens and of the $\mathrm{GP}_{\mathrm{v}}, \mathrm{SI}$, and LPO has been presented elsewhere (Swanson and Cowan, 1975; Swanson, 1976). For the sake of clarity, however, it may be useful to point out the major cytoarchitectonic criteria 

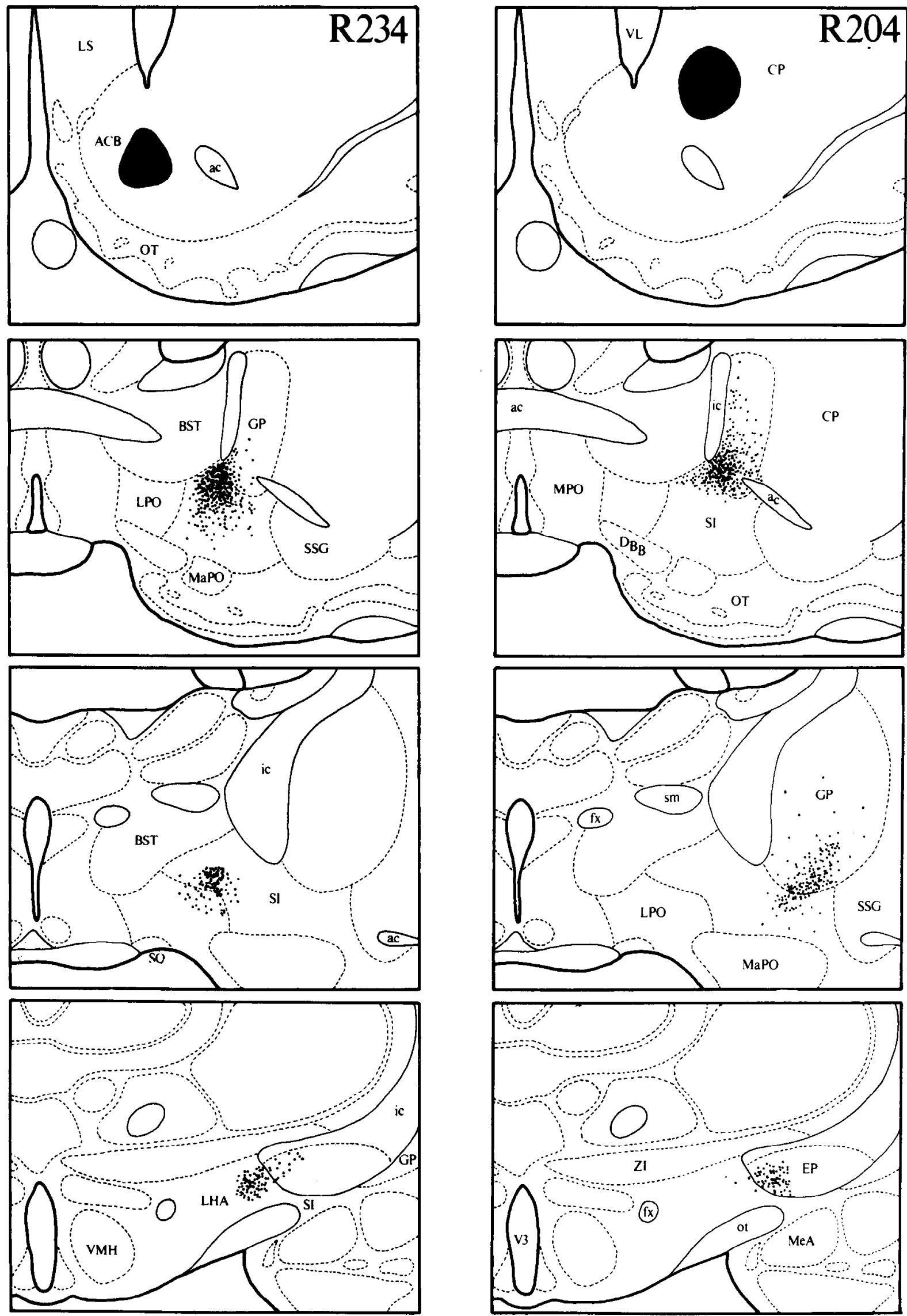

Figure 2. A comparison of the distribution of anterogradely transported label (dots) from ${ }^{3} \mathrm{H}$-amino acid injection sites (black areas) in the nucleus accumbens ( $A C B$; experiment $R 234)$ and in an adjacent part of the caudoputamen ( $C P$; experiment $R 204)$. As explained in the text, each brain was cut in approximately the same plane of section, and the results of each experiment were plotted on a standard series of drawings for ease of comparison. Drawings in each case are arranged from rostral (top) to caudal (bottom). 
that we have used to distinguish between the areas under consideration here.

As a rostromedial extension of the striatum, the neurons of the nucleus accumbens resemble those of the caudoputamen (Gưrdjian, 1928), and neurons in both regions project to the globus pallidus and to the substantia nigra (see Swanson and Cowan, 1975), although as indicated below, the nucleus accumbens has additional projections as well. There is no clear boundary between the two major divisions of the striatum of the rat, although most authors use for convenience a diagonal line that passes from the tip of the lateral ventricle, through the anterior commissure, to the ventrolateral edge of the caudoputamen (see Fig. 2, upper panel), a convention we have followed here.

The SI (Fig. 1) is a rather poorly defined cell group that lies ventral to, and is more or less coextensive with, the length of the globus pallidus (Fig. 2; Swanson, 1976); our material confirms that it consists primarily of large, scattered cells, many of which are acetylcholinesterase positive (see illustrations in Jacobowitz and Palkovits,
1974). We have thus defined the SI in the rat in relation to the better delineated cell groups that surround it (Swanson, 1976); for a review of the SI as defined in other species see Jones et al. (1976). The GP, on the other hand, has a lower density of cells, most of which are larger than those in the SI, and are not acetylcholinesterase positive, except medially along the lateral edge of the internal capsule (Jacobowitz and Palkovits, 1974). The LPO and LHA lie medial and ventral (respectively) to the SI and contain a moderate density of small- to medium-sized neurons.

Projections of the rostromedial striatum. The topographical organization of projections from the nucleus accumbens and adjacent regions of the caudoputamen to the GP and subpallidal region were investigated autoradiographically as a background to the electrophysiological experiments described below. The distribution of anterogradely transported label from discrete injection sites in the nucleus accumbens and in adjacent parts of the caudoputamen are compared in Figure 2. Fibers from the caudoputamen descend initially through a region
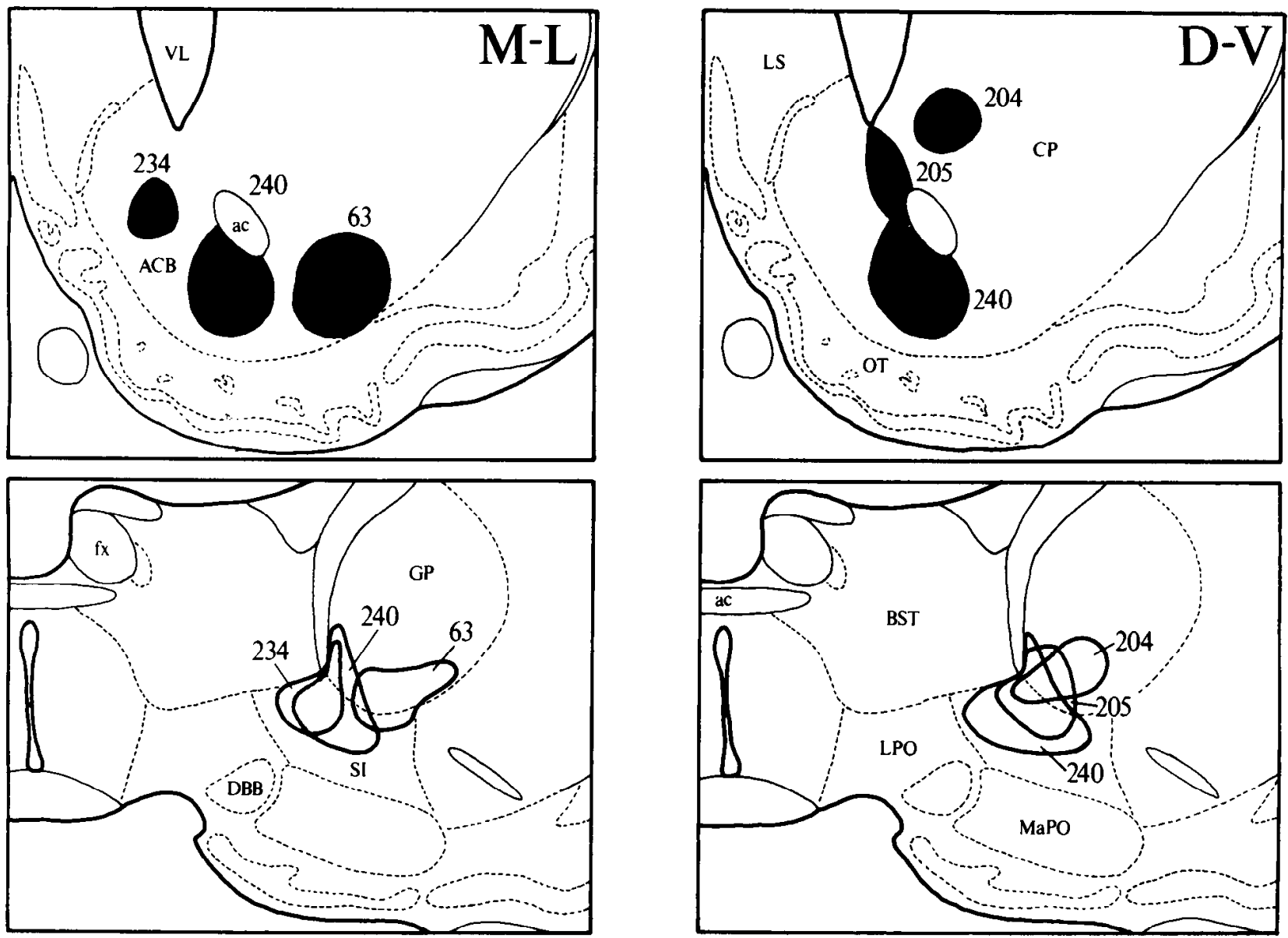

Figure 3. The results of five autoradiographic experiments are summarized in a schematic way to illustrate the topographical organization and convergence of fibers from the nucleus accumbens and adjacent parts of the caudoputamen in the globus pallidus and subpallidal region. Three progressively more lateral injection sites are shown in the upper left panel, and the progressively medial to lateral course of the labeled descending fibers is outlined in the lower left panel. In the upper right panel, a series of progressively more ventral injection sites is shown, and the labeled fibers, which are also arranged from dorsal to ventral, are shown in the lower right panel. These mediolateral $(M-L)$ and dorsoventral $(D \cdot V)$ gradients are maintained throughout the appropriate parts of the globus pallidus and subpallidal region. Note that the plane of section through the injection sites here is somewhat caudal to that shown in Figure 3, so that the two injection sites (R204 and R234) shown in each figure are somewhat different in size. 
that includes the $\mathrm{GP}_{\mathrm{v}}$ and immediately adjacent parts of the SI, before entering the entopeduncular nucleus and then the cerebral peduncle. In contrast, fibers from the nucleus accumbens descend initially through the medial half of the SI and the rostromedial tip of the GP before entering the LPO and then the LHA. The bottom panels of Figure 2 illustrate the major difference in the course of fibers from the nucleus accumbens and from the caudoputamen. On their way to the substantia nigra, most fibers from the latter structure pass through the LPO and LHA. It should be noted, however, that some of the label from the nucleus accumbens is seen over the medial part of the entopeduncular nucleus, and some of the label from adjacent parts of the caudoputamen is seen over the lateral edge of the LPO-LHA continuum. It should also be mentioned that while the pattern of anterogradely transported label suggests the presence of a terminal field in the GP and adjacent SI, it is not possible, at the light microscopic level, to establish unequivocally whether or not synapses occur along the pathways shown in Figure 2.

Observations from experiments in which ${ }^{3} \mathrm{H}$-amino acid injections were made into different sites in the nucleus accumbens and adjacent caudoputamen suggest two principles that appear to govern the topographic organization of labeled pathways through (and possibly to) the GP and adjacent regions (Fig. 3). First, these projections are organized along dorsoventral and mediolateral gradients. That is, neurons in medial parts of the nucleus accumbens project to medial parts of the GP, SI, and LPO (caudal to the level illustrated), while neurons in progressively more lateral parts of the nucleus accumbens project to progressively more lateral parts of the same regions. Second, fibers from adjacent parts of the rostromedial striatum overlap considerably, suggesting that there may be convergence upon single neurons in the $\mathrm{GP}_{\mathrm{v}}, \mathrm{SI}$, and LPO. It was not possible in the anatomical material to discern an anteroposterior gradient in the projections from the nucleus accumbens to the $\mathrm{GP}_{\mathrm{v}}$ and adjacent regions, perhaps because the nucleus accumbens lies just anterior to the regions under consideration. In contrast, the caudoputamen is considerably larger than the nucleus accumbens and essentially surrounds the GP. From the limited autoradiographic material available and from retrograde transport studies referred to below, it is clear that rostral parts of the caudoputamen project to rostral parts of the GP, whereas more caudal parts of the caudoputamen project to more caudal parts of the GP, as observed previously in the monkey (e.g., Szabo, 1962; Cowan and Powell, 1966).

True blue was injected into the GP, SI, or LPO in 16 animals to complement with a retrograde transport method the observations made with autoradiographic techniques. The results of these experiments have the limitation that fibers-of-passage to the midbrain, as well as terminals, may have taken up the tracer (Sawchenko and Swanson, 1981). In experiment GP1, the injection of true blue was centered in mid-rostrocaudal levels of the GP and did not spread to the ventralmost region of the GP or to the SI, or to the anterior or posterior thirds of the GP. In this experiment retrogradely labeled cells were observed in the dorsolateral part of the caudoputamen, at mid-rostrocaudal levels (Fig. 4). In contrast, an injection of true blue centered in the rostroventral tip of the GP and adjacent parts of the SI (see GP6 in Fig. 4) resulted in the retrograde labeling of cells throughout the nucleus accumbens, except for the most medial part of the nucleus (rostral to the level illustrated), and in adjacent regions of the caudoputamen. In experiment GP16, the injection was centered in the LPO and ventral parts of the bed nucleus of the stria terminalis, at the level shown in Figure 4. Retrogradely labeled cells in this
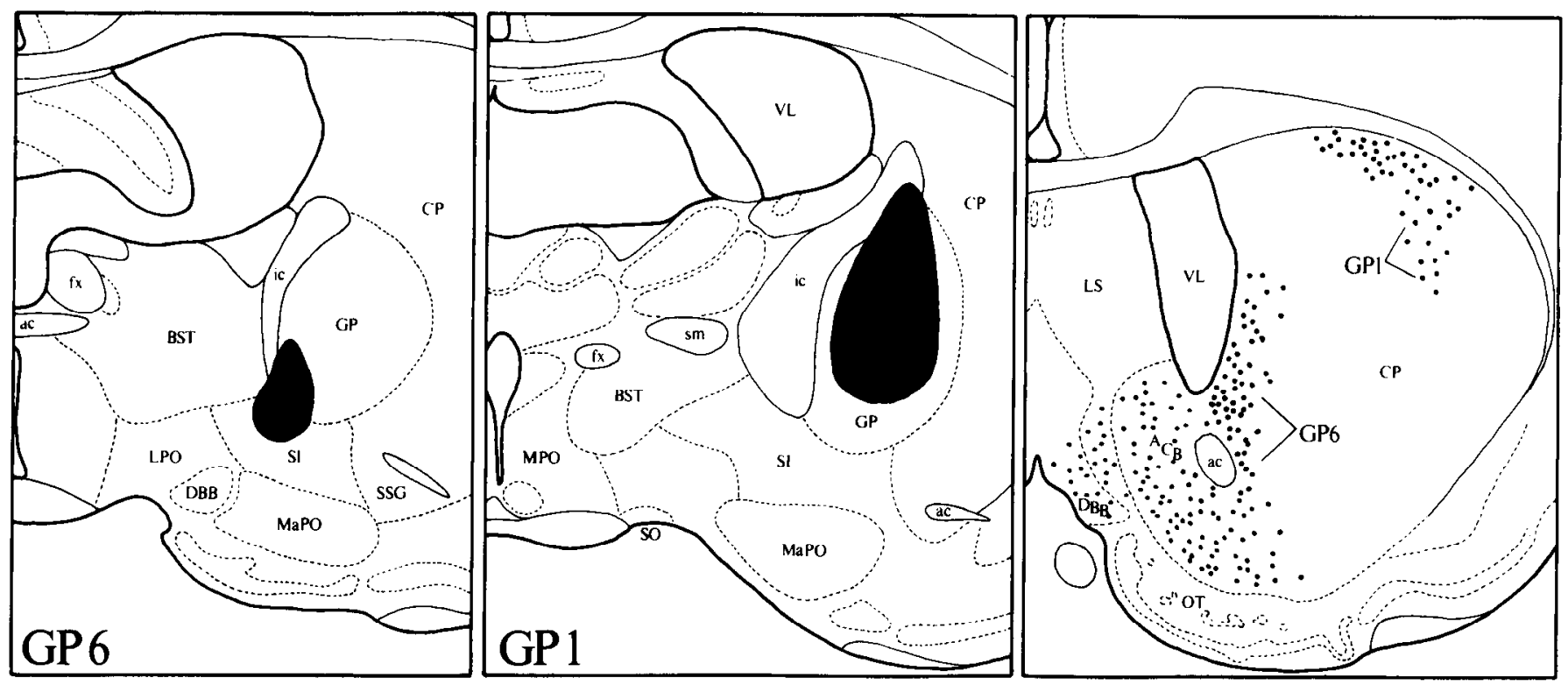

Figure 4. The distribution of retrogradely labeled cells at one level of the striatum (right panel) after injections of true blue centered in the middle part of the globus pallidus (experiment GPl; center panel) or into the anteroventral tip of the globus pallidus and adjacent parts of the substantia innominata (experiment GP6; left panel). An injection confined to the lateral preoptic area and bed nucleus of the stria terminalis (at the level shown in the left panel), which is not illustrated, only labeled cells in the nucleus accumbens. 
experiment were strictly confined to the nucleus accumbens.

In all of the experiments, only medium-sized neurons were retrogradely labeled in the striatum, unless the injection spread to the striatum itself. In such cases, a small number of large neurons also were retrogradely labeled.

Electrophysiological characteristics of neurons. Extracellular recordings were made from 205 neurons in the
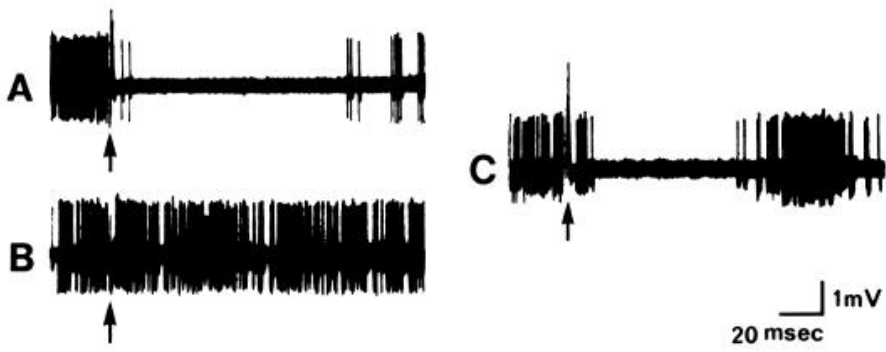

Figure 5. Action potentials recorded from single neurons in the ventromedial globus pallidus $\left(\mathrm{GP}_{\mathrm{v}}\right)$ and substantia innominata (SI). $A$, Inhibition of discharge of a neuron in the GP following single pulse stimulation of the nucleus accumbens shown by an arrow. B, Single pulse stimulation of the dorsolateral caudoputamen had no effect on the same $\mathrm{GP}_{\mathrm{v}}$ neuron. $C$, Inhibition of discharge of a neuron in the SI following single pulse stimulation of the nucleus accumbens.
$\mathrm{GP}_{\mathrm{v}}$ and adjacent parts of the SI, LPO, and LHA. The action potentials had a triphasic wave form and the spontaneous discharge rates varied from $0.6 \mathrm{~Hz}$ to $43 \mathrm{~Hz}$ (mean $=12.1 \mathrm{~Hz}$ ). The wave forms and rates of spontaneous discharge of these neurons were similar to those recorded from neurons in the $\mathrm{GP}_{\mathrm{d}}$.

Electrical stimulation of the nucleus accumbens. Single pulse stimulation of the nucleus accumbens was observed to reduce the rate of discharge of a large percentage of neurons in the $\mathrm{GP}_{\mathrm{v}}$ as well as in the SI, the LPO, and the LHA. An example of the inhibitory response of one of these neurons is shown in Figure $5 C$, the recording site in SI being shown in Figure 6C. The onset latency of the inhibitory effect of nucleus accumbens stimulation on this neuron was $11 \mathrm{msec}$. For most neurons the duration of the inhibitory effect increased as the intensity of stimulation in the nucleus accumbens was increased, as shown in Figure 7.

Another example of the inhibitory effect of accumbens stimulation is shown in Figure $5 A$. This neuron was in the $\mathrm{GP}_{\mathrm{v}}$ (see Fig. 6A). As shown in Figure $5 B$, the discharge rate of this neuron was not influenced by electrical stimulation of the dorsolateral caudoputamen.

Electrical stimulation of the nucleus accumbens had excitatory effects on some neurons in the subpallidal region. The onset latencies of these excitatory responses were similar to those of the inhibitory responses (range,

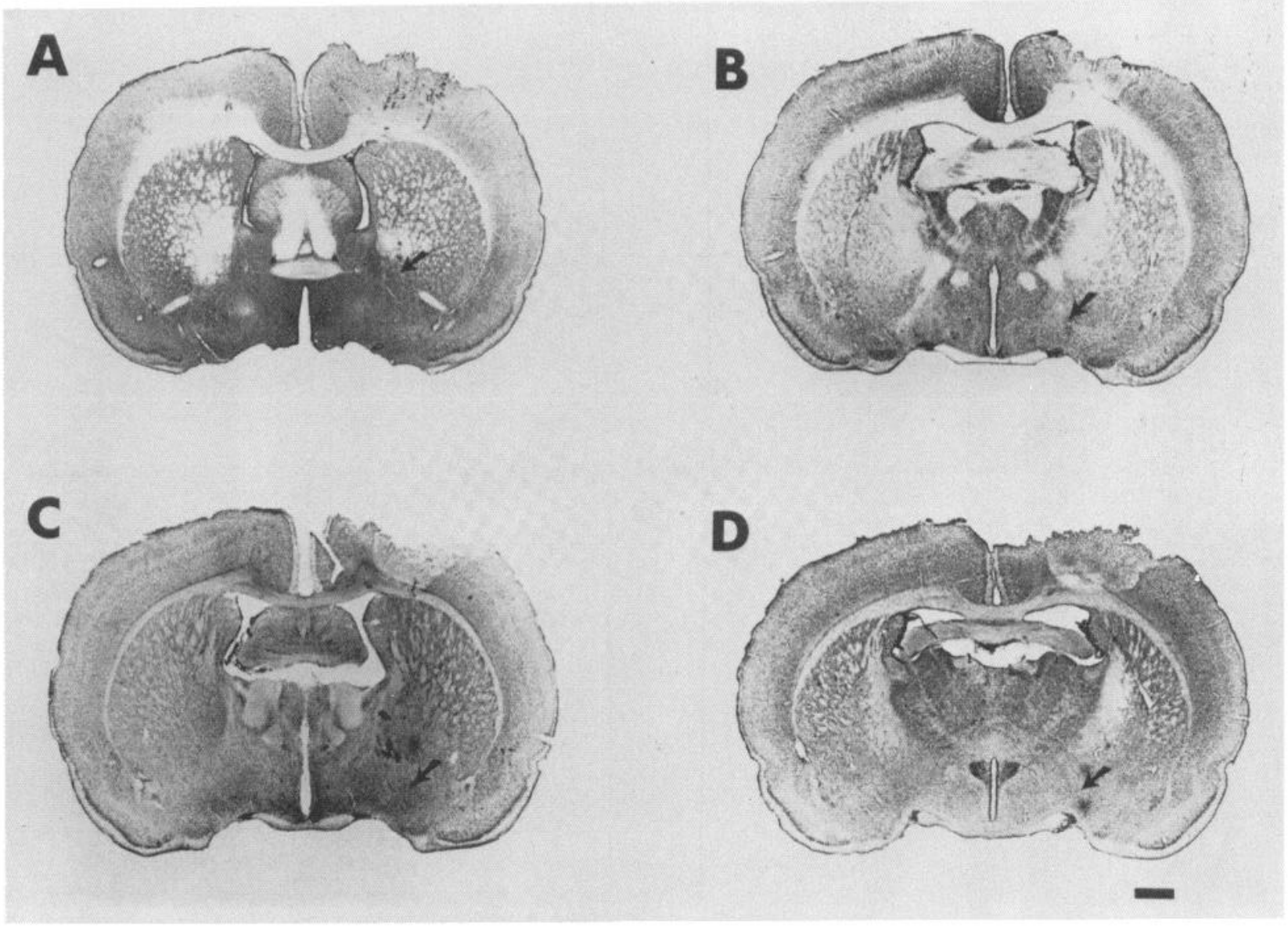

Figure 6. Recording sites of neurons inhibited by single pulse stimulation of the nucleus accumbens. $A$, Ventromedial aspect of the globus pallidus $\left(\mathrm{GP}_{\mathrm{v}}\right.$ ). $B$, Lateral preoptic area (LPO). $C$, Substantia innominata (SI). D, Lateral hypothalamic area (LHA). In each case the recording site is indicated by an arrow. 
1 to 30 msec; mean, $10.2 \mathrm{msec}$ ). However, as shown in Table I the occurrence of excitatory responses (19\%) was significantly less than that of inhibitory responses $(52 \%)$. Approximately one-quarter of the subpallidal neurons did not respond to single pulse stimulation of the nucleus accumbens.

In 12 of the electrophysiological recording experiments, two stimulating electrodes with a distance of $0.5 \mathrm{~mm}$ between them were positioned in the nucleus accumbens. For 23 neurons in the $\mathrm{GP}_{\mathrm{v}}$ and subpallidal region, inhibitory responses resulted from single pulse stimulation delivered through the medial as well as the lateral electrode. For 11 neurons an inhibitory response was observed with stimulation through one of the electrodes and an excitatory response was observed with stimulation through the other electrode. Thirty $\mathrm{GP}_{\mathrm{v}}$ neurons responded to stimulation delivered via one of the electrodes but not to stimulation via the second electrode, as shown in Figure 8. This observation is of special interest because it indicates that the spread of current was rather limited, not exceeding $0.5 \mathrm{~mm}$. In any case, 34 of this series of 64
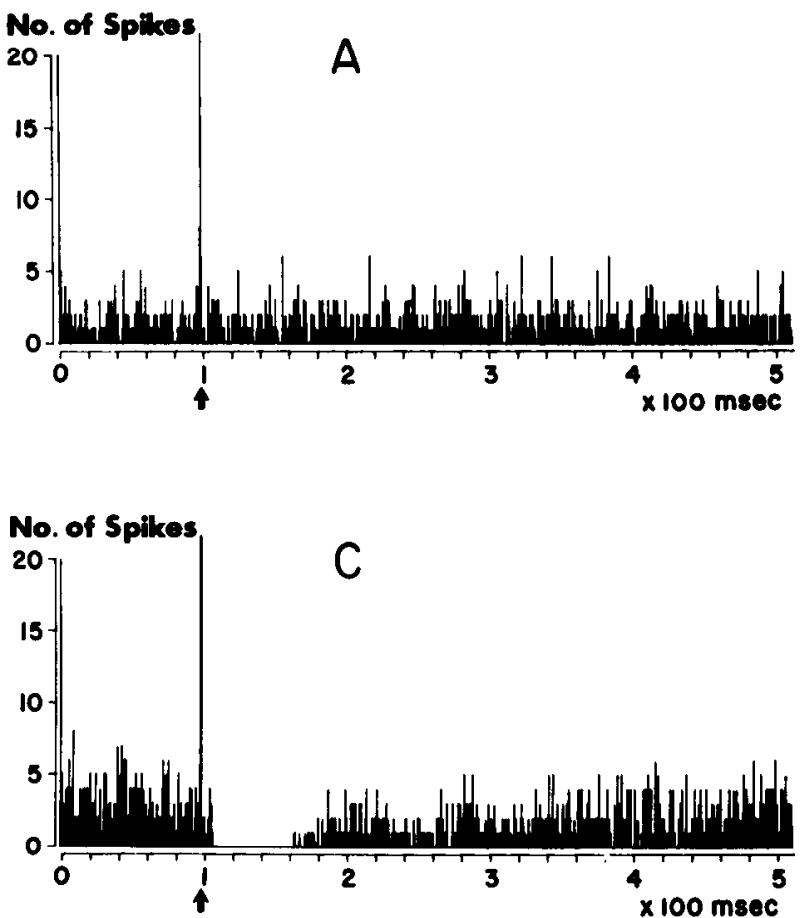

subpallidal neurons received converging inputs from two nucleus accumbens stimulation sites.

Recording sites in the subpallidal region. The most frequently occurring (or "typical") response of neurons in the GP, SI, LPO, and LHA to single pulse stimulation of the nucleus accumbens was an inhibitory effect with an onset latency of 6 to $18 \mathrm{msec}$. Such inhibitory responses are illustrated in Figures 5, 7, and 8, and examples of recording sites appear in Figure 6. The distribution of the series of 85 neurons showing this inhibitory response to nucleus accumbens stimulation is shown in Figure 9. From this it can be seen that there is a concentration of sites of inhibitory responses in the $\operatorname{GP}_{\mathrm{v}}(N=15)$ and in the adjacent SI $(N=34)$. These recording sites extend throughout the entire rostral-caudal extent of the GP. and SI. Also shown in Figure 9 are sites of inhibitory responses in the posterior part of the LPO $(n=14)$ and in parts of the LHA adjacent to the SI and the entopeduncular nucleus $(N=22)$. These four subpallidal regions $\left(\mathrm{GP}_{\mathrm{v}}, \mathrm{SI}, \mathrm{LPO}\right.$, and LHA) also contained recording sites for neurons that were activated by accumbens stimula-
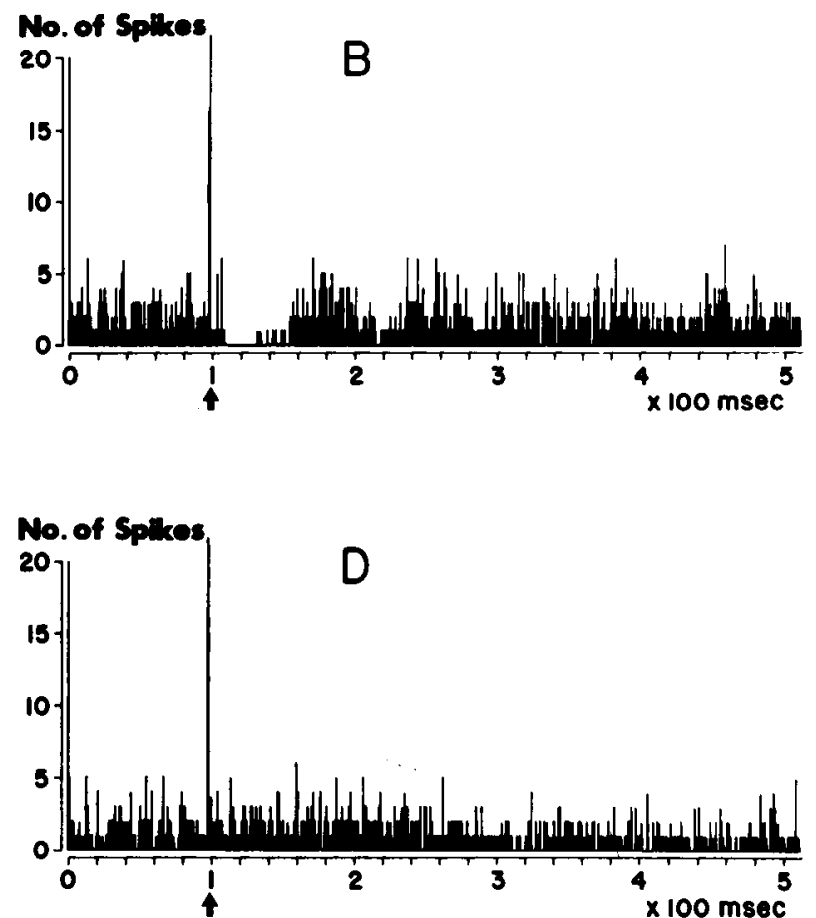

Figure 7. Post-stimulus histograms of action potentials recorded from a neuron in the substantia innominata (SI). Single pulse stimuli ( $0.15 \mathrm{msec}$ duration) were delivered to the nucleus accumbens with current intensities of $0.4 \mathrm{~mA}$ in $A, 0.5 \mathrm{~mA}$ in $B$, and $0.7 \mathrm{~mA}$ in $C$. Note the suppression of neuronal activity in $B$ and $C$ beginning after a latency of 9 msec. In $D$ there was no response of the same SI neuron when the dorsolateral caudoputamen was stimulated with a current intensity of $0.8 \mathrm{~mA}$. The stimulus pulse is shown by an arrow in each case. Histograms were compiled by a PDP-11/44 computer from 250 sweeps at $1.5 \mathrm{~Hz}$. The bin width was $1 \mathrm{msec}$.

TABLE I

Response of neurons in the globus pallidus and subpallidal region to electrical stimulation of the caudoputamen (CP) and nucleus accumbens

\begin{tabular}{|c|c|c|c|c|c|c|}
\hline & \multicolumn{2}{|c|}{ Dorsal Globus Pallidus } & \multicolumn{2}{|c|}{ Subpallidal Region } & \multicolumn{2}{|c|}{ Intermediate Region } \\
\hline & $\mathrm{CP}$ & Accumbens & $\mathrm{CP}$ & Accumbens & $\mathrm{CP}$ & Accumbens \\
\hline & $\%$ & $\%$ & $\%$ & $\%$ & $\%$ & $\%$ \\
\hline Inhibition & $73(68.2)$ & $25(14.3)$ & $31(22.6)$ & $154(52.5)$ & $13(40.6)$ & $18(31.0)$ \\
\hline No response & $18(16.8)$ & $148(84.6)$ & $95(69.4)$ & $84(28.7)$ & $14(43.8)$ & $36(62.1)$ \\
\hline
\end{tabular}



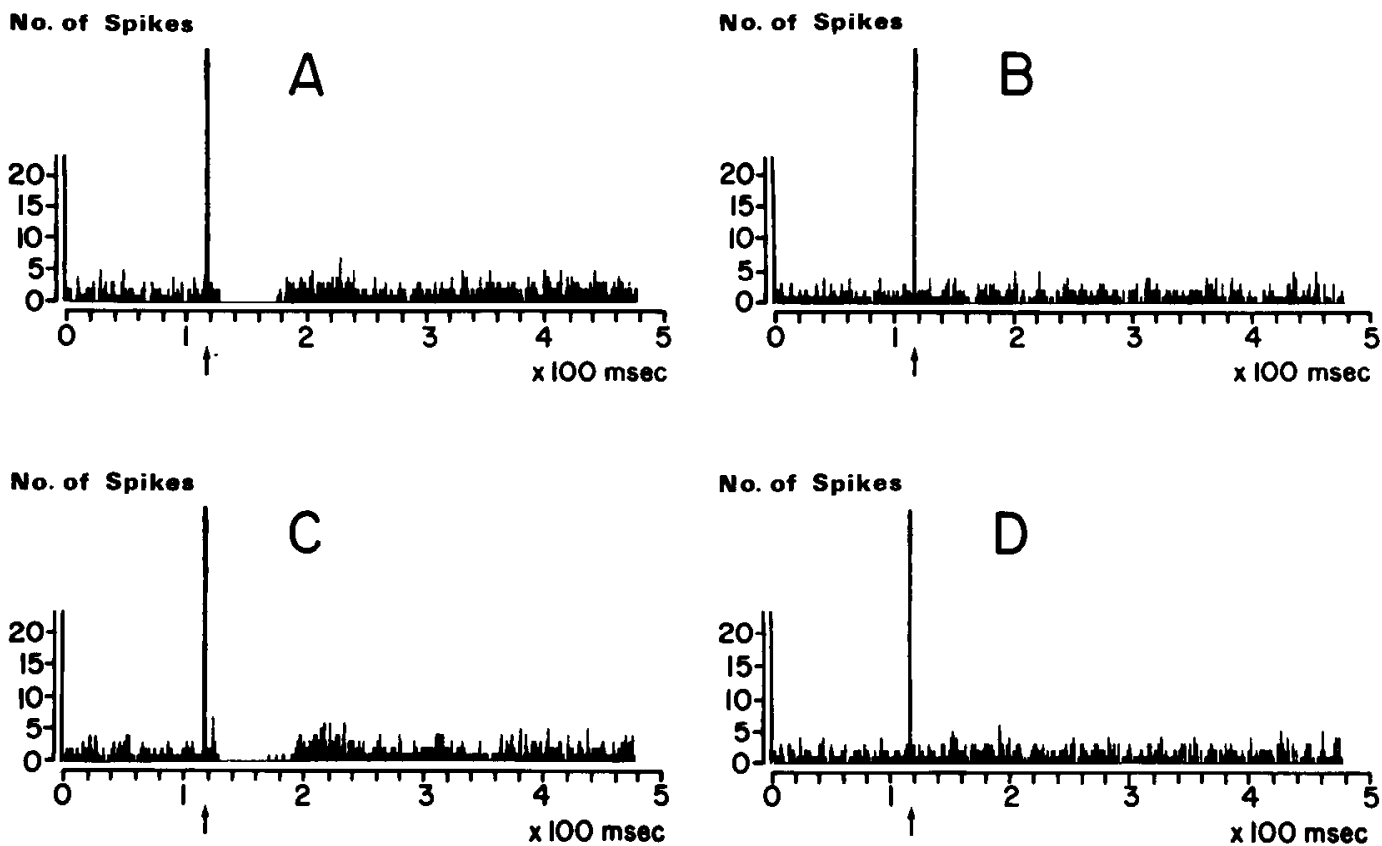

Figure 8. Post-stimulus histograms of action potentials recorded from a neuron in the ventral part of the globus pallidus (GP ). For histograms on the left, single pulse stimuli $(0.15 \mathrm{msec}$ duration) was delivered to the medial part of the nucleus accumbens with current intensities of $0.4 \mathrm{~mA}$ in $A$ and $0.6 \mathrm{~mA}$ in $C$. Note the inhibitory responses with an onset latency of $10.5 \mathrm{msec}$. For histograms on the right, single pulse stimuli $(0.15 \mathrm{msec}$ duration) were delivered to a site $0.5 \mathrm{~mm}$ more lateral in the nucleus accumbens with a current intensity of $0.4 \mathrm{~mA}$ in $B$ and $0.8 \mathrm{~mA}$ in $D$. Note the absence of responses.

tion as well as for neurons that did not respond (see Fig. 9).

Electrical stimulation of the caudoputamen. Single pulse stimulation of the dorsolateral caudoputamen resulted in inhibition of 73 of 107 neurons in the $\mathrm{GP}_{d}$ (see Table I). These stimulation sites corresponded to the region of retrogradely labeled neurons observed in experiment GP1 (see Fig. 4). A typical response is shown in Figure 10 in which the neuron did not respond to single pulse stimulation of the nucleus accumbens. As shown in Table I, whereas $68 \%$ of dorsal GP neurons were inhibited by stimulation of the dorsolateral caudoputamen, only $14 \%$ were inhibited by stimulation of the nucleus accumbens. The recording sites in the $\mathrm{GP}_{d}$ of neurons inhibited by caudoputamen stimulation are shown in Figure 11 along with recording sites of neurons which were excited (15\%) or which did not respond (17\%) to this stimulation.

\section{Discussion}

The major conclusions that can be drawn from the experiments reported here are that the nucleus accumbens projects in a topographically organized way to cells in the $\mathrm{GP}_{\mathrm{v}}$ and to an adjacent subpallidal region including the SI, LPO, and LHA, that a major component of this projection is inhibitory, and that single neurons in these areas may receive convergent inputs from adjacent parts of the nucleus accumbens and, in some cases, from adjacent parts of the caudoputamen as well.

It is well known that the projection from the caudate nucleus and putamen to the globus pallidus in the monkey is organized topographically (Szabo, 1962; Cowan and Powell, 1966), and the autoradiographic results presented here indicate that projections from the nucleus accumbens and adjacent parts of the caudoputamen to the $\mathrm{GP}_{\mathrm{v}}$ and subpallidal region in the rat are organized along both mediolateral and dorsoventral gradients with respect to both the cells of origin and the course of descending fibers. It is also clear, however, that fibers from adjacent, though separate parts of the nucleus accumbens overlap considerably in the $\mathrm{GP}_{\mathrm{v}}$ and subpallidal region.

There is no doubt that fibers from the caudoputamen form synapses upon neurons in the globus pallidus (for review see Graybiel and Ragsdale, 1979), and autoradiographic and electrophysiological evidence strongly suggests that the same is true for projections from the nucleus accumbens to the $\mathrm{GP}_{\mathrm{v}}$ (see the introduction). In addition, Heimer and Wilson (1975) reported that degenerating terminals, most of which were thought to contain flattenable vesicles, were observed electron microscopically in the SI (which corresponds to their "ventral pallidum") after lesions in the nucleus accumbens. However, similar studies have not been carried out along the course of descending fibers in the LPO and LHA, and it is not possible from the pattern of silver grains in autoradiographs to be certain whether fibers end in these regions or merely pass through. For this reason the striking correspondence between the recording sites in the present electrophysiological experiments and the terminal fields suggested by the anatomical experiments is of particular interest. Since the latencies of the inhibitory responses recorded from subpallidal neurons to nucleus accumbens stimulation (e.g., Figs. 5 and 6 ) were similar to the latencies of antidromic activation of nucleus accumbens neurons following subpallidal stimulation (Jones and Mogenson, 1980b), it seems likely that they were mediated by direct connections. This conclusion is strengthened by the fact that, as far as we are aware, 
A

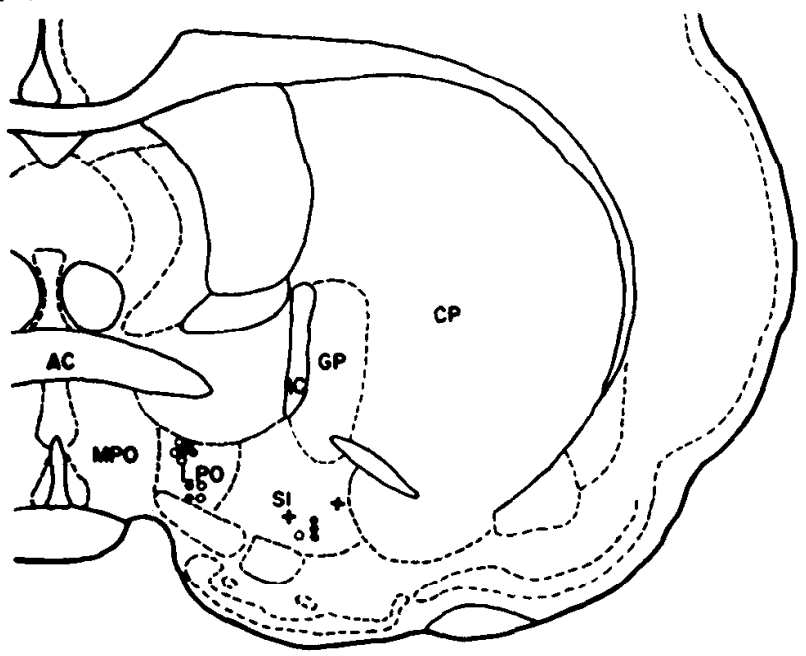

C

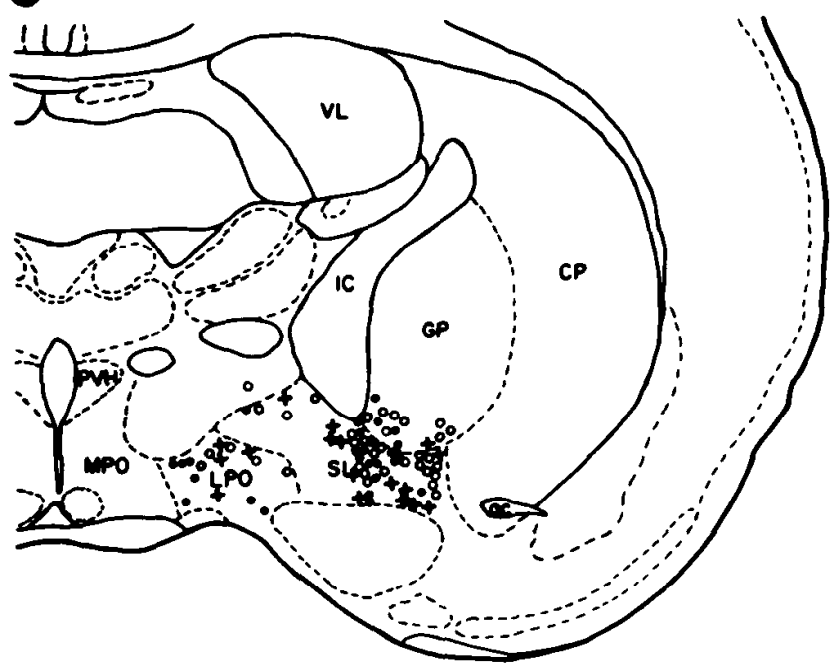

E

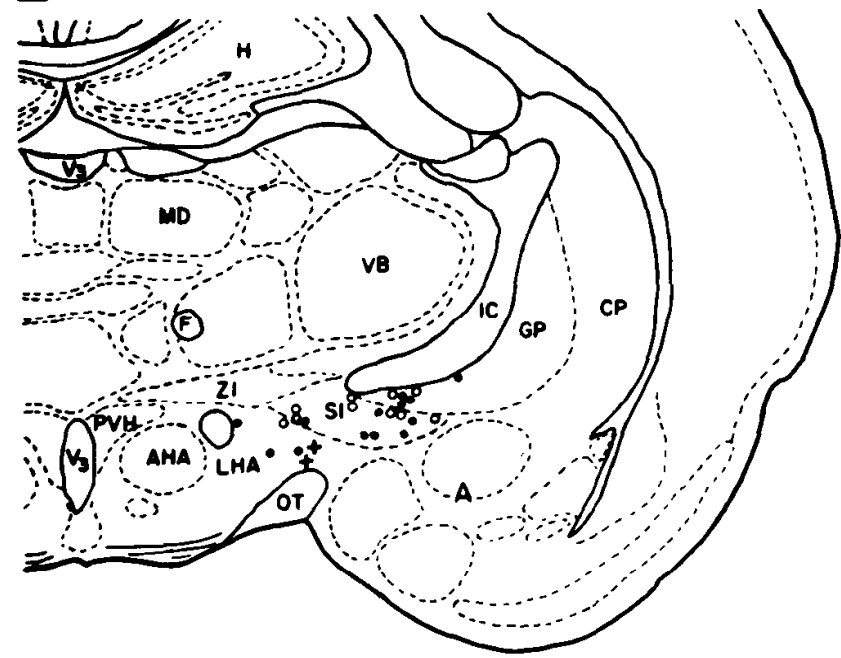

B

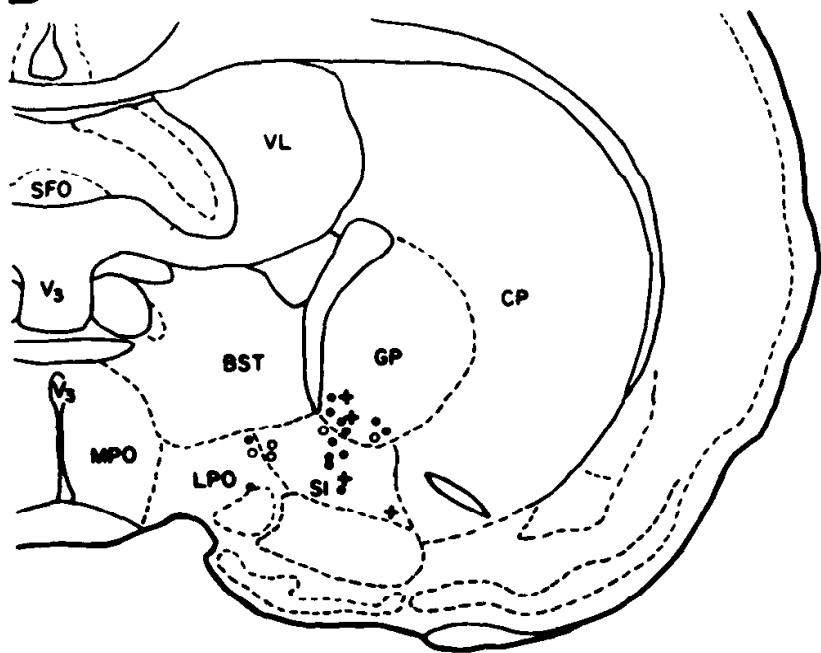

D

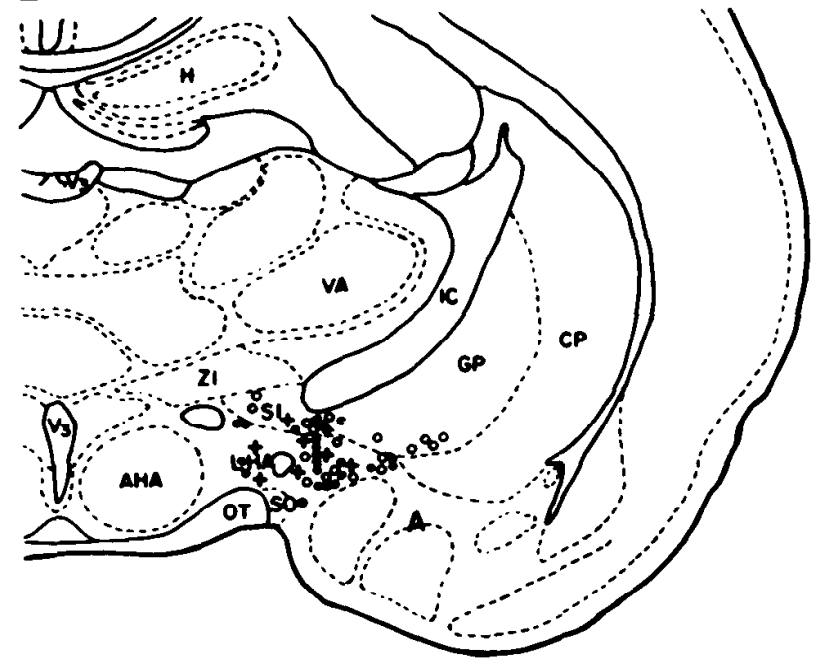

$\mathbf{F}$

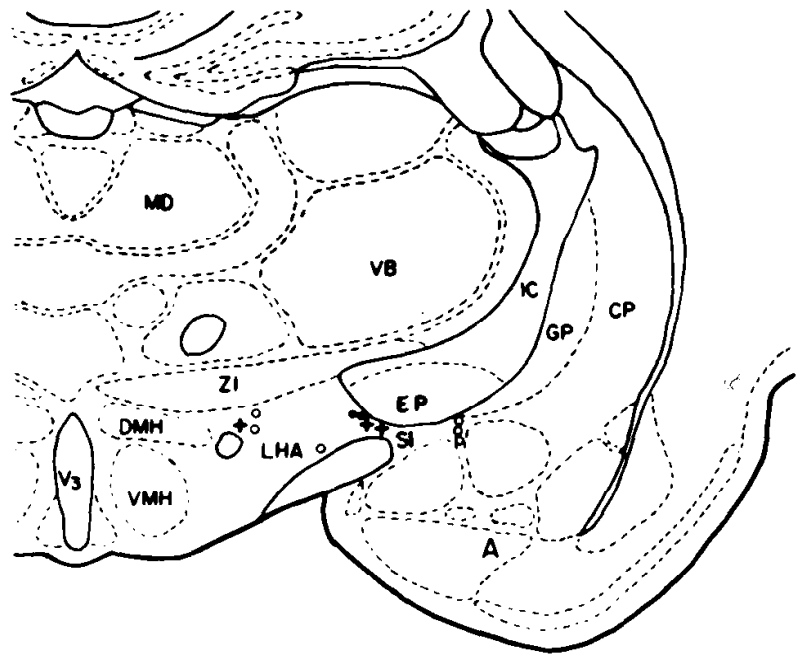

Figure 9. Recording sites for subpallidal neurons which were inhibited (black dots) or excited (crosses) by single pulse stimulation of the nucleus accumbens with the onset latencies of the inhibition in the range from 6 to 18 msec. There is a stimulation of the nucleus accumbens $\mathrm{GP}_{\mathrm{v}}$ and in the adjacent SI. Also note the responsive sites in the LPO and LHA. These subpallidal regions also contained neurons (recording sites indicated by open circles) that did not respond to single pulse stimulation of the nucleus accumbens. 

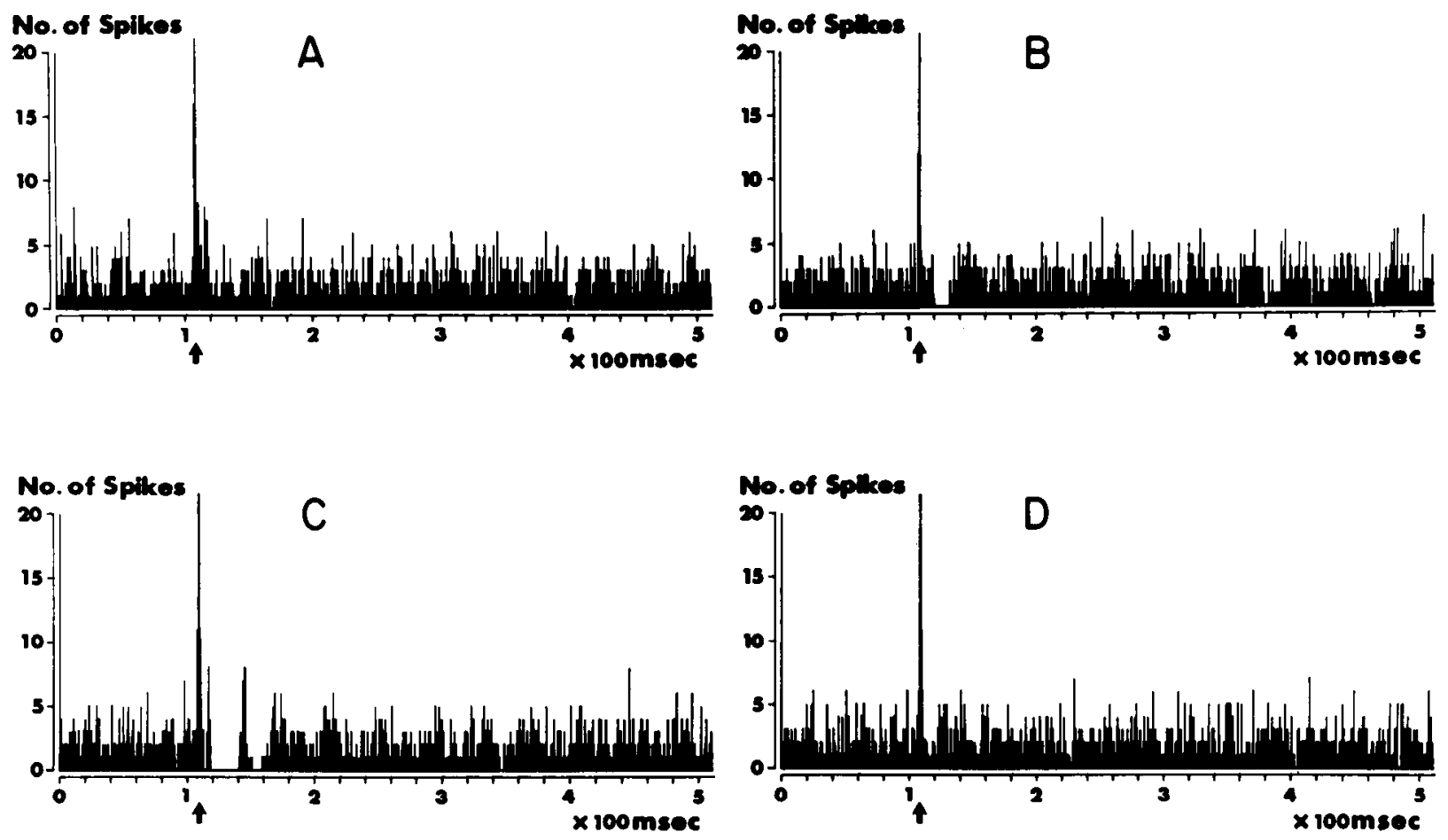

Figure 10. Post-stimulus histograms of action potentials recorded from a neuron in the dorsal region of the globus pallidus $\left(\mathrm{GP}_{\mathrm{d}}\right)$. Single pulse stimuli (0.15 msec duration) were delivered to the dorsolateral caudoputamen with current intensities of 0.4 $\mathrm{mA}$ in $A, 0.5 \mathrm{~mA}$ in $B$, and $0.7 \mathrm{~mA}$ in $C$. Note the suppression of neuronal activity in each case, followed in $C$ by a small excitation. In $D$ there was no response of the same $\mathrm{GP}_{\mathrm{d}}$ neuron when the nucleus accumbens was stimulated with a current intensity of 0.7 $\mathrm{mA}$.

there are no known pathways that descend through the nucleus accumbens to enter the medial forebrain bundle. Accordingly, the results of the electrophysiological recording experiments complement the observations obtained with the axonal transport techniques.

The stimulation sites in the nucleus accumbens were mainly in a region 0.2 to $0.7 \mathrm{~mm}$ medial to the anterior commissure, and in previous autoradiographic experiments this region was shown to project to the ventromedial globus pallidus and adjacent SI (Swanson and Cowan, 1975; Conrad and Pfaff, 1976; Nauta et al., 1978; Newman and Winans, 1980). Also, in electrophysiological recording experiments stimulation of this region of the nucleus accumbens was observed to influence the spontaneous activity of neurons in the GP $\mathrm{v}$ and SI, with many of the responses being suppression of spontaneous neuronal activity (Dray and Oakley, 1978; Jones and Mogenson, 1980b). The results of the present study confirm and extend these earlier findings. As shown in Table I, more than $70 \%$ of the neurons recorded from in the subpallidal region responded to single pulse stimulation of the nucleus accumbens, with inhibition occurring in approximately three-quarters of the responsive neurons. The most frequently observed response to nucleus accumbens stimulation, illustrated in Figures 5, 7, and 8, was recorded from neurons in the $\mathrm{GP}_{\mathrm{V}}$ and SI, as well as from caudal parts of the LPO and rostral parts of the LHA. The recording sites of these responses, shown in Figure 9 , are subpallidal regions that are very similar to those demonstrated by axonal transport experiments as presented in Figures 2 and 4.

The stimulation sites in the dorsolateral caudoputa- men were selected because, as shown in Figure 4, experiments using the retrograde transport of true blue indicated that this was the source of neurons that project to the main body of the globus pallidus. It was not surprising, therefore, that more than $80 \%$ of the neurons recorded from in the $\mathrm{GP}_{\mathrm{d}}$ responded to single pulse stimulation of the dorsolateral caudoputamen (see Table I). The observation that the response was inhibition for twothirds of the responsive $\mathrm{GP}_{\mathrm{d}}$ neurons is consistent with previous electrophysiological recording experiments (Malliani and Purpura, 1967; Ohye et al., 1976). Based on electrophysiological and neurochemical evidence, reviewed by Dray (1980, p. 261), it seems likely that these inhibitory responses of $\mathrm{GP}_{d}$ neurons to single pulse stimulation of the dorsolateral caudoputamen are GABA mediated.

There is some preliminary evidence to suggest that the inhibitory responses, recorded from neurons of $\mathrm{GP}_{\mathrm{v}}$ in response to single pulse stimulation of the nucleus accumbens (shown in Figs. 5, 7, and 8), are also GABA mediated. This is based on observations that these inhibitory responses are attenuated by the iontophoretic application of the GABA antagonists bicuculline and picrotoxin (Dray and Oakley, 1978; Jones and Mogenson, $1980 \mathrm{~b}$ ) and that GABA is depleted in the $\mathrm{GP}_{\mathrm{v}}$ after lesions of the nucleus accumbens (Fonnum and Walaas, 1981). Similar electrophysiological and neurochemical experiments are needed to see whether the inhibitory responses recorded from neurons in SI, LPO, and LHA to nucleus accumbens stimulation are GABA mediated.

Considerable anatomical evidence (see Beckstead et al., 1979) indicates that there is a transitional zone be- 
A

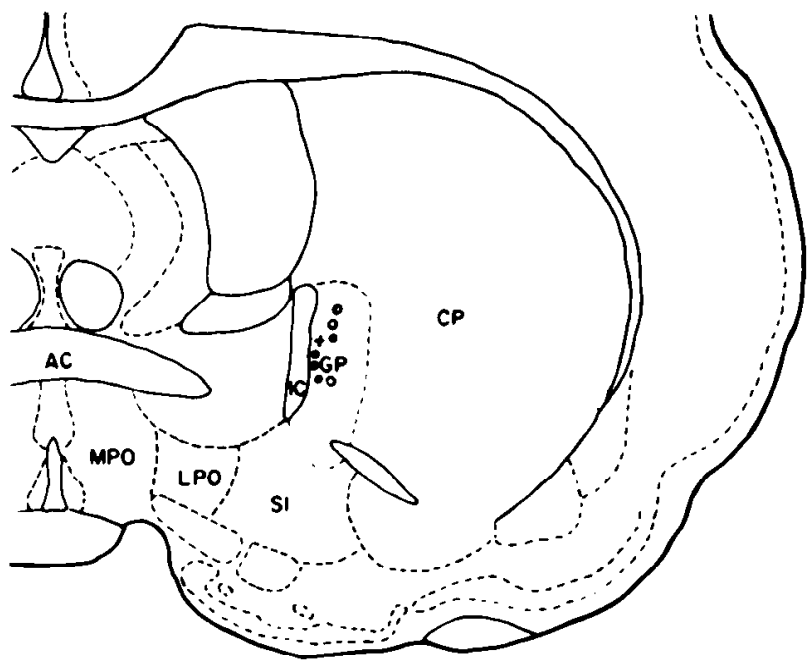

C

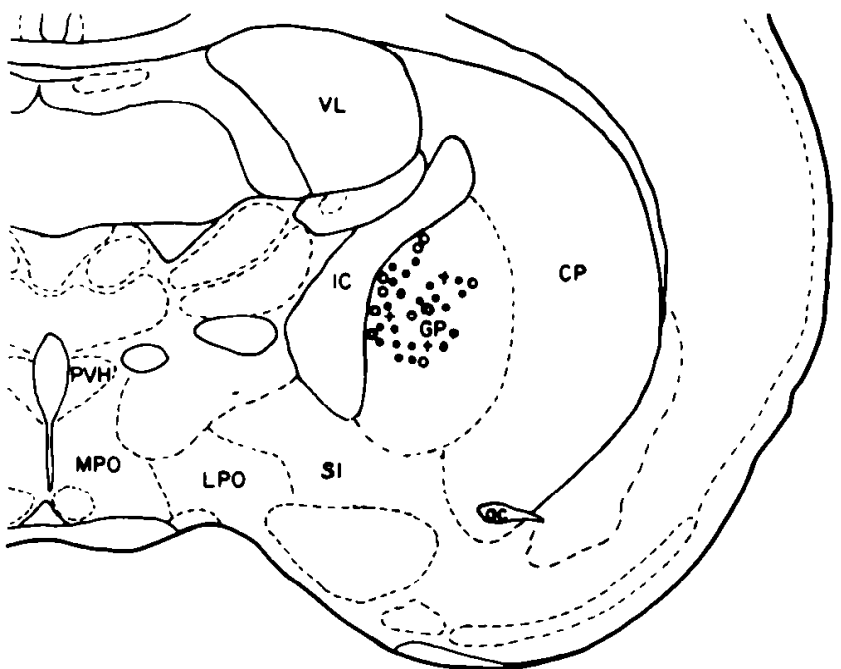

B

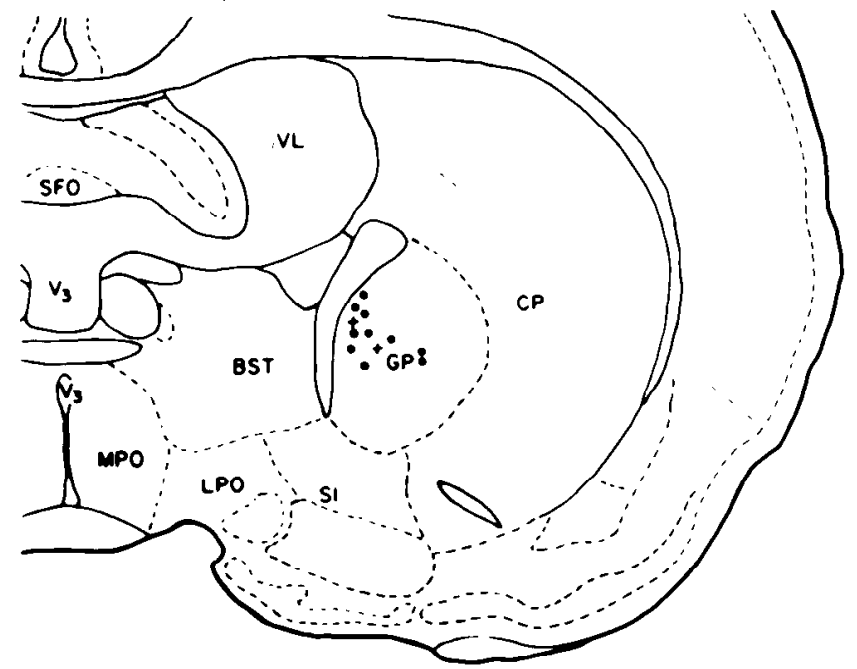

D

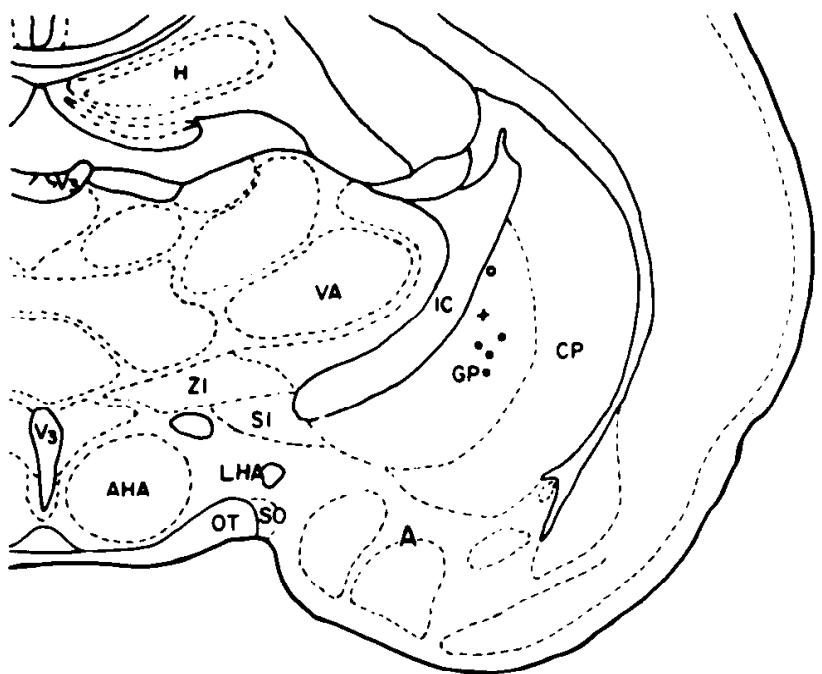

Figure 11. Recording sites for neurons of the globus pallidus that were inhibited (black dots) or excited (crosses) by single pulse stimulation of the caudoputamen with onset latencies of the inhibition in the range from 6 to 18 msec. Also shown (by open circles) are recording sites of neurons that did not respond to caudoputamen stimulation.

tween what is clearly the caudoputamen and what is clearly the nucleus accumbens, so that there is no obvious morphological boundary between the two. Therefore, the electrophysiological responses of neurons in a corresponding transitional region between the $\mathrm{GP}_{\mathrm{d}}$ and the subpallidal region to stimulation of the caudoputamen and the nucleus accumbens were analyzed separately. As shown in Table I, the pattern of responses here fell between those of neurons in the $\mathrm{GP}_{d}$ and the subpallidal region. Caudoputamen stimulation produced an inhibitory response in $40 \%$ of these neurons, as compared to $68 \%$ for $\mathrm{GP}_{\mathrm{d}}$ neurons and $22 \%$ for subpallidal neurons. Nucleus accumbens stimulation produced an inhibitory response in $31 \%$ of these neurons as compared to $14 \%$ for $\mathrm{GP}_{\mathrm{d}}$ neurons and $52 \%$ for subpallidal neurons. These electrophysiological observations are consistent with the demonstration of anatomical projections to this intermediate region from both the nucleus accumbens and the caudoputamen (see Fig. 4).
It is of interest that injections of picrotoxin centered in the subpallidal region initiate locomotor activity in rats (Mogenson et al., 1980). Since locomotor activity also is initiated by injections of dopamine and amphetamine into the nucleus accumbens (Pijnenberg and van Rossum, 1973; Jones et al., 1981), an effect that is blocked by pretreating the subpallidal region with GABA (Jones and Mogenson, 1980a), it appears that a dopaminergic projection to the nucleus accumbens (primarily from the ventral tegmental area) and a GABAergic projection from the latter to the subpallidal region may play a role in behavioral response initiation. As summarized in Figure 12, autoradiographic evidence (Swanson, 1976) suggests that such responses may be mediated at least in part by projections from the SI, LPO, and LHA to the midbrain reticular formation, including the so-called mesencephalic locomotor region as defined in the cat by Grillner and Shik (1973). Electrical stimulation of the lateral hypothalamic and lateral preoptic regions at low 


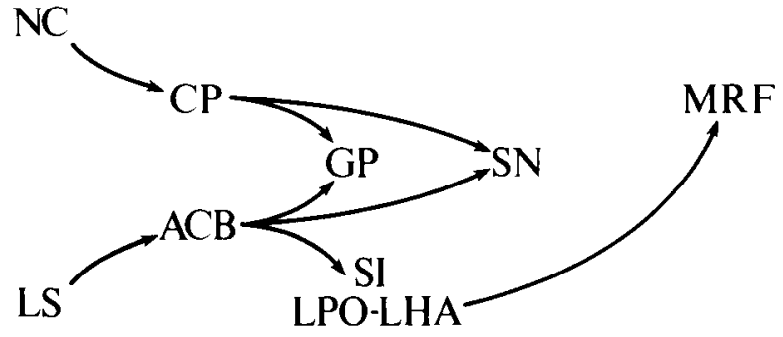

Figure 12. This diagram illustrates some of the major connections of the basal ganglia discussed in the text. The caudoputamen $(C P)$ receives inputs from all parts of the neocortex and projects to the globus pallidus $(G P)$ and substantia nigra $(S N)$. On the other hand, the nucleus accumbens $(A C B)$ receives inputs from limbic parts of the telencephalon $(L S)$ and projects to ventral parts of the globus pallidus, the subpallidal region (SI, LPO-LHA), and medial parts of the substantia nigra. In addition, cells in adjacent parts of the $C P$ and $A C B$ appear to project to individual cells in ventral parts of the $G P$. The subpallidal region may play an important role in the relay of information from the $A C B$ to parts of the midbrain reticular formation $(M R F)$ involved in somatomotor control systems. For simplicity, projections from the $G P$ to the thalamus and projections from the thalamus and brainstem to the basal ganglia are not shown.

current intensities has been shown to elicit movement and what might be considered "exploratory" locomotor responses (Roberts and Carey, 1965; Christopher and Butler, 1968; Phillips et al., 1969; Bland and Vanderwolf, 1972), and Malmo and Malmo (1977) have shown that multiple unit activity recorded simultaneously from the LPO and dorsal parts of the midbrain reticular formation are correlated significantly with head and body movements. In contrast to the nucleus accumbens, stimulation of the caudoputamen in the rat is associated with stereotyped behaviors, such as grooming, rather than locomotion (Kelly et al., 1975). It is tempting to speculate that these differential responses are mediated by different projections from the nucleus accumbens and the caudoputamen, and the present results suggest that these may involve a pathway from the former to the subpallidal region and a pathway from the latter to the globus pallidus itself, which in turn projects to the ventral lateral nucleus of the thalamus and the subthalamic nucleus (see Graybiel and Ragsdale, 1979). On the other hand, the circling behavior that may result from striatal manipulation is now thought to involve projections to the substantia nigra (see Graybiel and Ragsdale, 1979; Imperato et al., 1981). It may also be worth pointing out that the nucleus accumbens projects to the SI, which is thought to give rise to a widespread though diffuse cholinergic input to the cerebral cortex (see Lehmann et al., 1980 ), although the functional significance of this pathway is not yet clear.

Thus, the nucleus accumbens, which receives inputs from the amygdala (see Krettek and Price, 1978) and the hippocampal formation (see Swanson and Cowan, 1977), and the caudoputamen, which receives inputs from all parts of the neocortex (see Webster, 1961), have differential outputs which may help to explain why stimulation of these two parts of the striatum lead to different types of behavioral response. The forward progression associated with locomotor activity is a fundamental component of food and water procurement, attack, and other goaldirected behaviors to which limbic regions of the telencephalon and the hypothalamus are known to contribute (Mogenson and Huang, 1973). Accordingly, it may be suggested that the pathway from the nucleus accumbens to the subpallidal region shown in Figure 12 may be part of the circuits that relate integrative limbic activities with somatomotor mechanisms.

\section{References}

Beckstead, R. M., V. B. Domesick, and W. J. H. Nauta (1979) Efferent connections of the substantia nigra and ventral tegmental area in the rat. Brain Res. 175: 191-217.

Bland, B. H., and C. H. Vanderwolf (1972) Diencephalic and hippocampal mechanisms of motor activity in the rat: Effects of posterior hypothalamic stimulation on behavior and hippocampal slow wave activity. Brain Res. 43: 67-88.

Christopher, S. M., and C. M. Butler (1968) Consummatory behaviors and locomotor exploration evoked by self-stimulation sites in rats. J. Comp. Physiol. Psychol. 66: 335-339.

Conrad, L. C. A., and D. W. Pfaff (1976) Efferents from medial basal forebrain and hypothalamus in the rat. II. An autoradiographic study of the anterior hypothalamus. J. Comp. Neurol. 169: 221-262.

Cowan, W. M., and T. P. S. Powell (1966) Strio-pallidal projections in the monkey. J. Neurol. Neurosurg. Psychiatry 29: 426-439.

Cowan, W. M., D. I. Gottlieb, A. E. Hendrickson, J. L. Price, and T. A. Woolsey (1972) The autoradiographic demonstration of axonal connections in the central nervous system. Brain Res. 37: 21-51.

Dray, A. (1980) The physiology and pharmacology of mammalian basal ganglia. Prog. Neurobiol. 14: 221-335.

Dray, A., and N. R. Oakley (1978) Projections from nucleus accumbens to globus pallidus and substantia nigra in the rat. Experientia 34: 68-70.

Fonnum, F., and I. Walaas (1981) Localization of neurotransmitters in nucleus accumbens. In The Neurobiology of the Nucleus Accumbens, R. B. Chronister and J. F. DeFrance, eds., pp. 259-272, The Haer Institute, Brunswick, ME.

Graybiel, A. M., and C. W. Ragsdale (1979) Fiber connections of the basal ganglia. Prog. Brain Res. 51: 239-283.

Grillner, S., and M. I. Shik (1973) On the descending control of the lumbosacral spinal cord from the "mesencephalic locomotor region." Acta Physiol. Scand. 87: 320-333.

Gurdjian, E. C. (1928) The corpus striatum of the rat. J. Comp. Neurol. 45: 249-281.

Heimer, L., and R. D. Wilson (1975) The subcortical projections of the allocortex: Similarities in the neural associations of the hippocampus, the piriform cortex, and the neocortex. In Golgi Centennial Symposium Proceedings, M. Santini, ed., pp. 177-193, Raven Press, New York.

Imperato, A., M. L. Porceddu, M. Morelli, G. Faa, and G. DiChiara (1981) Role of dorsal mesencephalic reticular formation and deep layers of the superior colliculus as output stations for turning behavior elicited from the substantia nigra pars reticulata. Brain Res. 216: 437-443.

Jacobowitz, D. M., and M. Palkovits (1974) Topographic atlas of catecholamine and acetylcholinesterase-containing neurons in the rat brain. I. Forebrain (telencephalon, diencephalon). J. Comp. Neurol. 157: 13-28.

Jones, D. L., and G. J. Mogenson (1980a) Nucleus accumbens to globus pallidus GABA projection subserving ambulatory activity. Am. J. Physiol. 238: R63-R69.

Jones, D. L., and G. J. Mogenson (1980b) Nucleus accumbens to globus pallidus GABA projection: Electrophysiological and iontophoretic investigations. Brain Res. 188: 93-105.

Jones, D. L., G. J. Mogenson, and M. Wu (1981) Injections of 
dopaminergic, cholinergic, serotoninergic and gabaergic drugs into the nucleus accumbens: Effects on locomotor activity in the rat. Neuropharmacology 20: 29-37.

Jones, E. G., H. Burton, C. B. Saper, and L. W. Swanson (1976) Midbrain, diencephalic and cortical relationships of the basal nucleus of Meynert and associated structures in primates. J. Comp. Neurol. 167: 385-420.

Kelly, P. H., P. W. Seviour, and S. D. Iversen (1975) Amphetamine and apomorphine responses in the rat following 6OHDA lesions of the nucleus accumbens septi and corpus striatum. Brain Res. 94: 507-522.

Kemp, J. M., and T. P. S. Powell (1971) The connexions of the striatum and globus pallidus: Synthesis and speculation. Philos. Trans. R. Soc. Lond. (Biol.) 262: 441-457.

Krettek, J. E., and J. L. Price (1978) Amygdaloid projections to subcortical structures within the basal forebrain and brainstem in the rat and cat. J. Comp. Neurol. 178: 225-254.

Lehmann, J., J. I. Nagy, S. Atmadja, and H. G. Fibiger (1980) The nucleus basalis magnocellularis: The origin of a cholinergic projection to the neocortex of the rat. Neuroscience 5 : 1161-1174.

Maeda, H., and G. J. Mogenson (1980) An electrophysiological study of inputs to neurons of the ventral tegmental area from the nucleus accumbens and medial preoptic-anterior hypothalamic area. Brain Res. 197: 365-377.

Malliani, A., and D. P. Purpura (1967) Intracellular studies of the corpus striatum. II. Patterns of synaptic activities in lenticular and entopeduncular neurons. Brain Res. 6: 341354.

Malmo, H. P., and R. B. Malmo (1977) Movement-related forebrain and midbrain multiple unit activity in rats. Electroencephalogr. Clin. Neurophysiol. 42: 501-509.

Mogenson, G. J., and Y. H. Huang (1973) The neurobiology of motivated behavior. Prog. Neurobiol. 1: 53-83.

Mogenson, G. J., D. L. Jones, and C. Y. Yim (1980) From motivation to action: Functional interface between the limbic system and the motor system. Prog. Neurobiol. 14: 69-97.

Nagy, J. I., D. A. Carter, and H. C. Fibiger (1978) Anterior striatal projections to the globus pallidus, entopeduncular nucleus and substantia nigra: The GABA connection. Brain Res. 158: 15-29.

Nauta, W. J. H., G. P. Smith, V. B. Domesick, and R. L. M. Faull (1978) Efferent connections and nigral afferents of the nucleus accumbens septi in the rat. Neuroscience 3: 385-401.

Newman, R., and S. S. Winans (1980) An experimental study of the ventral striatum of the golden hamster. I. Neuronal connections of the nucleus accumbens. J. Comp. Neurol. 191: 167-192.
Ohye, C., G. LeGuyader, and J. Feger (1976) Responses of subthalamic and pallidal neurons to striatal stimulation: An extracellular study on awake monkeys. Brain Res. 111: 241252.

Phillips, A. G., V. C. Cox, J. W. Kakolewski, and E. S. Valenstein (1969) Elicitation of object carrying by rats: An approach to understanding the behavior produced by brain stimulation. Science 166: 903-905.

Pijnenburg, A. J. J., and J. M. van Rossum (1973) Stimulation of locomotor activity following injection of dopamine into the nucleus accumbens. J. Pharm. Pharmacol. 25: 1003-1005.

Roberts, W. W., and R. J. Carey (1965) Rewarding effect of performance of gnawing aroused by hypothalamic stimulation in the rat. J. Comp. Physiol. Psychol. 59: 317-324.

Sawchenko, P. E., and L. W. Swanson (1981) A method for tracing biochemically defined pathways in the central nervous system using combined fluorescence retrograde transport and immunohistochemical techniques. Brain Res. 210: 31-51.

Schmued, L. C., L. W. Swanson, and P. E. Sawchenko (1982) Some fluorescent counterstains for neuroanatomical studies. J. Histochem. Cytochem. 30: 123-128.

Swanson, L. W. (1976) An autoradiographic study of the efferent connections of the preoptic region in the rat. J. Comp. Neurol. 167: 227-256.

Swanson, L. W., and W. M. Cowan (1975) A note on the connections and development of the nucleus accumbens. Brain Res. 92: 324-330.

Swanson, L. W., and W. M. Cowan (1977) An autoradiographic study of the organization of the efferent connections of the hippocampal formation in the rat. J. Comp. Neurol. 172: 4984.

Swanson, L. W., and W. M. Cowan (1979) The connections of the septal region in the rat. J. Comp. Neurol. 186: 621-656.

Swanson, L. W., and G. J. Mogenson (1981) Neural mechanisms for the functional coupling of autonomic, endocrine and somatomotor responses in adaptive behavior. Brain Rev. 3: 134.

Szabo, J. (1962) Topical distribution of the striatal efferents in the monkey. Exp. Neurol. 5: 21-36.

Voneida, T. J. (1960) An experimental study of the course and destination of fibres arising in the head of the caudate nucleus in the cat and monkey. J. Comp. Neurol. 115: 75-87.

Webster, K. E. (1961) Cortico-striate interrelations in the albino rat. J. Anat. 95: 329-337.

Yim, C. Y., and G. J. Mogenson (1980) Electrophysiological studies of neurons in the ventral tegmental area of Tsai. Brain Res. 181: 301-313. 